\title{
Tribological Performance Optimization of Al-7.5\% SiCp Composites Using the Taguchi Method and Grey Relational Analysis
}

\author{
Shouvik Ghosh, Prasanta Sahoo, and Goutam Sutradhar \\ Department of Mechanical Engineering, Jadavpur University, Kolkata 700032, India \\ Correspondence should be addressed to Prasanta Sahoo; psjume@gmail.com
}

Received 11 May 2013; Accepted 7 August 2013

Academic Editor: Masamichi Kawai

Copyright (c) 2013 Shouvik Ghosh et al. This is an open access article distributed under the Creative Commons Attribution License, which permits unrestricted use, distribution, and reproduction in any medium, provided the original work is properly cited.

The present study considers an experimental study of tribological performance of Al-7.5\% SiCp metal matrix composite and optimization of tribological testing parameters based on the Taguchi method coupled with grey relational analysis. A grey relational grade obtained from grey relational analysis is used as a performance index to study the behaviour of Al-7.5\% SiCp MMC with respect to friction and wear characteristics. The tribological experiments are carried out by utilizing the combinations of tribological test parameters based on the $\mathrm{L}_{27}$ Taguchi orthogonal design with three test parameters, namely, load, speed, and time. The material Al-7.5\% SiCp metal matrix composite is developed by reinforcing LM6 aluminium alloy with 7.5\% (by weight) SiC particle of 400 mesh size $(\sim 37 \mu \mathrm{m})$ in an electric melting furnace. It is observed that sliding time has a significant contribution in controlling the friction and wear behaviour of Al-7.5\% SiCp MMC. Furthermore, all the interactions between the parameters have significant influence on tribological performance. A confirmation test is also carried out to verify the accuracy of the results obtained through the optimization problem. In addition, a scanning electron microscopy (SEM) test is performed on the wear tracks to study the wear mechanism.

\section{Introduction}

In recent years, metal matrix composites have gained popularity for use in industrial applications. The metal matrix composites have become increasingly desirable to engineers, largely due to improved toughness, strength, and stiffness properties offered by these materials relative to the unreinforced base metals. Mostly light metals such as aluminium, magnesium, and their alloys have received the commercial recognition due to their relatively low cost and easy processing. Arguably, aluminium based composites have shown performance improvements in a variety of applications requiring high strength, low mass, and tailored thermal properties. In the past years, many researchers have studied the friction and wear behaviour of Al based composites. Mostly, researchers have studied the friction and wear behaviour for sliding contact [1-6]. Some of the researchers have studied the abrasive wear behaviour for the same [7-12]. The effect of heat treatment $[13,14]$ and temperature change [15] is also studied by some researchers.
Ma et al. [1] conducted wear test with block-on-ring configuration for $\mathrm{Al}-20 \% \mathrm{SiCp}$ (particulate) and $\mathrm{Al}-50 \% \mathrm{SiCp}$. From the tests, they reported that wear increases with the increase in load and sliding speed, while wear decreases with the increase in $\mathrm{SiC}$ incorporation. It was also observed that at loads of above $100 \mathrm{~N}$ and at sliding speed of $6 \mathrm{~m} / \mathrm{s}$ severe wear took place. Yalcin and Akbulut [2] observed that wear rate varies inversely with reinforcement volume fraction. Sharma et al. [3] conducted the dry wear test for $\mathrm{SiC}$ reinforcement 0 5 volume fraction range and observed that wear rates decrease with increase in volume fraction of the reinforcement. Ghosh et al. [4] studied the friction behaviour of $\mathrm{Al}-5 \% \mathrm{SiC}$ MMC and concluded that applied load and sliding speed are the most significant parameters affecting the friction behaviour of the material. Another similar study was conducted by Ghosh et al. [5] on the friction behaviour of $\mathrm{Al}-10 \% \mathrm{SiC}$ MMC. Onat [6] studied the dry sliding wear properties of $\mathrm{SiCp}$ reinforced $\mathrm{Al}-\mathrm{Cu}$ composite and concluded that with increase in applied load and sliding speed, the wear rates 
increased. Ahlatci et al. [7] carried out abrasive test of Al$8 \% \mathrm{SiC}$ MMC by abrasive wear tester. Sahin [8] studied the abrasive wear behaviour of Al-SiC composite and optimized the testing parameters using Taguchi method. In another study, Şahin [9] performed abrasive wear test of Al-15\% SiC at different loads, sliding distances, and reinforcement particles size. The researcher observed that reinforcement particle size has the greatest effect on wear. Al-Rubaie et al. [10] performed wear test on two body abrasion wear models. The tests were conducted with $\mathrm{SiC}$ reinforcement having mean size of 10, 27, and $43 \mu \mathrm{m}$. The reinforcement is mixed with $\mathrm{Al}$ in the proportion of 5, 10, and 20 vol.\%. From the results, it was observed that wear resistance of the MMC increases with increase in particle size of the $\mathrm{SiC}$ reinforcement. In another similar study, Al-Rubaie et al. [11] studied three body abrasion of Al$\mathrm{SiC}$ using a thin oil film as lubricant between the sample and the rotating disk. Howell and Ball [12] performed dry wear tests using $\mathrm{Al}-20 \% \mathrm{SiC}$ against brake pads. From the results, it was concluded that inclusion of reinforcement enhanced the wear resistance of the material alloy. The effect of matrix alloy on the wear behaviour of the composite was studied by Rao and Das [13]. The experimental study was conducted using AA7010, AA7009, and AA2024 aluminium alloys, and reinforcement volume fraction was varied from 10 to $25 \%$. The test showed that the increase in volume fraction of reinforcement decreased the wear rate. In another study by Rao and Das [14], it was concluded that heat treatment of the composites improved the friction and wear property of the composite. Martín et al. [15] studied wear behaviour in the temperature range of $20-200^{\circ} \mathrm{C}$ and noted that heat treatment did not modify substantially the wear resistance of the composites. Another study on the influence of temperature on the wear behaviour of $\mathrm{Al}$ base composites was conducted by Straffelini et al. [16]. The researcher concluded that external heating decreased both friction and wear for the composite material.

For the present tribological study, aluminium alloy LM6 is used as base metal, and silicon carbide ( $\mathrm{SiCp}$ ) is used as reinforcement. The MMC is synthesized by stir casting process in an electric melting furnace where silicon carbide ( $7.5 \%$ by wt.) is introduced into the aluminium alloy. The tribological tests are conducted on the material to study the friction and wear properties of the material. The result data are generalized to grey relational grade and analyzed by the Taguchi Method. A statistical analysis of variance (ANOVA) is performed. Finally, confirmation test is carried out to verify the optimal process parameters combination. The microstructure study is carried out with the help of SEM to judge the wear mode of the material.

\section{The Taguchi Method}

The Taguchi method [17-19] is a powerful tool for designing high quality systems based on orthogonal array (OA) experiments that provide much reduced variance for the experiments with an optimum setting of process control parameters. It introduces an integrated approach that is simple and efficient to find the best range of designs for quality, performance, and computational cost. This method achieves the integration of design of experiments (DOE) [20] with the parametric optimization of the process yielding the desired results. The traditional experimental design procedures focus on the average process performance characteristics, but the Taguchi method concentrates on the effect of variation on the process quality characteristics rather than on its averages. That is, the Taguchi approach makes the process performance insensitive (robust) to variation in uncontrolled or noise factors. Taguchi recommends that this can be done by the proper design of parameters during the "parameter design" phase of off-line quality control. He designed certain standard OAs by which simultaneous and independent valuation of two or more parameters for their ability to affect the variability of a particular product or process characteristic can be done in a minimum number of tests. Using OA, the Taguchi method explores the entire design space through a small number of experiments in order to determine all of the parameter effects and several of the interactions. These data are then used to predict the optimum combination of the design parameters that will minimize the objective function and satisfy all the constraints. In addition to locating a near optimum objective function, the Taguchi method provides information on parameter trends and noise sensitivities thereby enabling a robust design. The parameter design phase of the Taguchi method generally includes the following steps: (1) identify the objective of the experiment; (2) identify the quality characteristic (performance measure) and its measurement systems; (3) identify the factors that may influence the quality characteristic, their levels, and possible interactions; (4) select the appropriate $\mathrm{OA}$ and assign the factors at their levels to the OA; (5) conduct the test described by the trials in the $\mathrm{OA}$; (6) analysis of the experimental data using the signal-tonoise $(S / N)$ ratio, factor effects, and the analysis of variance (ANOVA) to see which factors are statistically significant and to find the optimum levels of factors; (7) verification of the optimal design parameters through confirmation experiment. The $\mathrm{OA}$ requires a set of well-balanced (minimum experimental runs) experiments. The Taguchi method uses a statistical measure of performance called $(S / N)$ ratios, which are logarithmic functions of desired output to serve as objective functions for optimization. The $S / N$ ratio takes both the mean and the variability into account and is defined as the ratio of the mean (signal) to the standard deviation (noise). The ratio depends on the quality characteristics of the product/process to be optimized. The three categories of $S / N$ ratios are used: lower the better (LB), higher the better (HB), and nominal the best (NB). The parameter level combination that maximizes the appropriate $S / N$ ratio is the optimal setting. For the case of minimization of wear, LB characteristic needs to be used. Furthermore, a statistical analysis of variance (ANOVA) [21] is performed to find which process parameters are statistically significant. With the $S / N$ ratio and ANOVA analyses, the optimal combination of the process parameters can be predicted. Finally, a confirmation experiment is conducted to verify the optimal process parameters obtained from the parameter design. 
TABLE 1: Chemical composition of LM6.

\begin{tabular}{|c|c|c|c|c|c|c|c|c|c|}
\hline Elements (\%) & Si (10-13) & $\mathrm{Cu}(0.1)$ & $\mathrm{Fe}(0.6)$ & $\operatorname{Mn}(0.5)$ & $\mathrm{Zn}(0.1)$ & $\mathrm{Pb}(0.1)$ & $\mathrm{Ni}(0.1)$ & $\operatorname{Mg}(0.1)$ & $\operatorname{Ti}(0.2)$ \\
\hline
\end{tabular}

\section{Grey Relational Analysis}

The aim of the present paper is to optimize the tribological test parameters with the objective to minimize both friction and wear of Al-7.5\% SiCp. Thus, it is a case of multiresponse optimization, which is different from that of a single performance characteristic. The higher $S / N$ ratio for one performance characteristic may correspond to a lower $S / N$ ratio for another. Therefore, the overall evaluation of the $S / N$ ratio is required for the optimization of multiple performance characteristics. Grey relational analysis [22] is an efficient tool for such multiresponse analysis. In grey relational analysis, the first step is to perform the grey relational generation in which the results of the experiments are normalized in the range between 0 and 1 . Then, the second step is to calculate the grey relational coefficient from the normalized data to represent the correlation between the desired and actual experimental data. The overall grey relational grade is then computed by averaging the grey relational coefficient corresponding to each performance characteristic. Overall evaluation of the multiple performance characteristics is based on the calculated grey relational grade. As a result, optimization of the complicated multiple performance characteristics is converted into optimization of a single grey relational grade. The optimal level of the process parameters is the level with the highest grey relational grade.

Furthermore, analysis of variance (ANOVA) is performed to predict the importance and significance of each process parameter and their interactions on the tribological properties of $\mathrm{Al}-7.5 \% \mathrm{SiCp}$ metal matrix composite. Finally, confirmation test is performed to verify the optimal combination of process parameter obtained from the analysis.

\section{Experimental Details}

4.1. Fabrication Process. The metal matrix composite is fabricated using LM6 as matrix metal and silicon carbide particle (size $\sim 37 \mu \mathrm{m}$ ) as reinforcement. The chemical composition of the matrix metal (LM6) is given in Table 1. The fabricating process used for this purpose is liquid stir casting technique which is simple and less expensive. The matrix metal LM6 is melted in clay graphite crucible using an electric resistance furnace. To increase the fluidity of the liquid metal by $3 \%$ weight magnesium is added. This addition of magnesium will also increase the bonding power by decreasing the surface energy (wetting angle) between the matrix alloy and the reinforcement particles. The silicon carbide particle is preheated at $850-900^{\circ} \mathrm{C}$ for $2-3 \mathrm{hrs}$ before mixing in the molten metal. The melt is then mechanically stirred using a mild steel impeller and then the preheated $\mathrm{SiC}$ particles are added to the stirred liquid metal. The mixing process is carried out at $750^{\circ} \mathrm{C}$ with a stirring speed of $400-500 \mathrm{rpm}$. Then, the molten mixture is poured into green silica sand mould. And after cooling, the samples required for tribological testing are prepared by different machining processes.
TABLE 2: Design factors used in the experiment.

\begin{tabular}{lcccc}
\hline Design factors & Unit & \multicolumn{3}{c}{ Levels } \\
& & 1 & 2 & 3 \\
\hline Load $(L)$ & $\mathrm{N}$ & 50 & $75^{\mathrm{i}}$ & 100 \\
Speed $(S)$ & $\mathrm{RPM}$ & 180 & $200^{\mathrm{i}}$ & 220 \\
Time $(T)$ & $\mathrm{MIN}$ & 20 & $30^{\mathrm{i}}$ & 40 \\
\hline
\end{tabular}

Initial testing condition.

4.2. Design of Experiment. Design factors or control factors are those which are varied during the experimental tests. There are a number of control factors that can affect the tribological behaviour of Al-7.5\% SiCp. For this experimental purpose, the control factors chosen are load, speed, and time since these are the significant ones. Table 2 shows the design factors with their levels. The present study considers the friction and wear characteristics of Al-7.5\% SiCp as the response variable. It may be noted here that the levels chosen for the design factors (load, speed, and time) are not very similar to real life applications. Typically, all these parameters have been selected at lower levels as compared to real life applications. This is due to the limitation of the tribotester used in the experimentation.

Based on the Taguchi method, an orthogonal array (OA) is considered to reduce the number of experiments required to determine the optimal friction and wear for $\mathrm{Al}-7.5 \% \mathrm{SiCp}$ metal matrix composite. To choose an orthogonal array, the total number of degrees of freedom is to be chosen. For this experimental purpose, $\mathrm{L}_{27}$ orthogonal array is chosen. This $\mathrm{L}_{27} \mathrm{OA}$ has 27 rows corresponding to the number of tests, and the degree of freedom is 26 . The degree of freedom of each design factor is 2, and for two-way interaction of the factors, the degree of freedom is 4 . So, the total degree of freedom for the conducted experiment is $(2 \times 3+4 \times 3=18)$.

So, the $\mathrm{L}_{27} \mathrm{OA}$ is chosen for the experimental purpose. The 1st column is assigned to load $(L), 2$ nd column is assigned to speed $(S)$, and the 3 rd column is assigned to time $(T)$. The rest of the columns are assigned to the two-way interactions of the factors and error terms. Table 3 shows the orthogonal array along with the experimental results for friction and wear.

4.3. Tribological Test. The tribological tests are carried out in a multitribotester TR25 (Ducom, India) (Figure 1) under dry nonlubricated condition and at ambient temperature $\left(28^{\circ} \mathrm{C}\right)$. It uses a block-on-roller configuration where EN32 steel roller is used. The Al-SiCp samples (size $20 \mathrm{~mm} \times 20 \mathrm{~mm} \times$ $8 \mathrm{~mm}$ ) are pressed against a rotating steel roller (diameter $50 \mathrm{~mm}$, thickness $50 \mathrm{~mm}$ ) of hardness $65 \mathrm{HRc}$. The setup is placed in such a way that the rotating roller serves as the counter face material and stationary plate serves as the test specimen. Figure 2 shows the close-up view of specimen in multitribotester. A 1:5 ratio loading lever is used to apply normal load on top specimen. The loading lever is pivoted 
TABLE 3: $\mathrm{L}_{27}$ orthogonal array with design factors and interactions assigned.

\begin{tabular}{|c|c|c|c|c|c|c|c|c|c|c|c|c|c|c|c|}
\hline Trial no & $1(L)$ & $2(S)$ & $3(L \times S)$ & $4(L \times S)$ & $5(T)$ & $6(L \times T)$ & $7(L \times T)$ & $8(S \times T)$ & 9- & $10-$ & $11(S \times T)$ & $12-$ & 13- & $\mathrm{COF}$ & Wear $(\mu \mathrm{m})$ \\
\hline 1 & 1 & 1 & 1 & 1 & 1 & 1 & 1 & 1 & 1 & 1 & 1 & 1 & 1 & 0.341 & 60.07 \\
\hline 2 & 1 & 1 & 1 & 1 & 2 & 2 & 2 & 2 & 2 & 2 & 2 & 2 & 2 & 0.321 & 71.84 \\
\hline 3 & 1 & 1 & 1 & 1 & 3 & 3 & 3 & 3 & 3 & 3 & 3 & 3 & 3 & 0.387 & 85.24 \\
\hline 4 & 1 & 2 & 2 & 2 & 1 & 1 & 1 & 2 & 2 & 2 & 3 & 3 & 3 & 0.323 & 79.44 \\
\hline 5 & 1 & 2 & 2 & 2 & 2 & 2 & 2 & 3 & 3 & 3 & 1 & 1 & 1 & 0.373 & 94.89 \\
\hline 6 & 1 & 2 & 2 & 2 & 3 & 3 & 3 & 1 & 1 & 1 & 2 & 2 & 2 & 0.303 & 107.9 \\
\hline 7 & 1 & 3 & 3 & 3 & 1 & 1 & 1 & 3 & 3 & 3 & 2 & 2 & 2 & 0.316 & 50.14 \\
\hline 8 & 1 & 3 & 3 & 3 & 2 & 2 & 2 & 1 & 1 & 1 & 3 & 3 & 3 & 0.348 & 69.63 \\
\hline 9 & 1 & 3 & 3 & 3 & 3 & 3 & 3 & 2 & 2 & 2 & 1 & 1 & 1 & 0.312 & 86.03 \\
\hline 10 & 2 & 1 & 2 & 3 & 1 & 2 & 3 & 1 & 2 & 3 & 1 & 2 & 3 & 0.396 & 50.63 \\
\hline 11 & 2 & 1 & 2 & 3 & 2 & 3 & 1 & 2 & 3 & 1 & 2 & 3 & 1 & 0.469 & 61.39 \\
\hline 12 & 2 & 1 & 2 & 3 & 3 & 1 & 2 & 3 & 1 & 2 & 3 & 1 & 2 & 0.462 & 77.16 \\
\hline 13 & 2 & 2 & 3 & 1 & 1 & 2 & 3 & 2 & 3 & 1 & 3 & 1 & 2 & 0.397 & 64.45 \\
\hline 14 & 2 & 2 & 3 & 1 & 2 & 3 & 1 & 3 & 1 & 2 & 1 & 2 & 3 & 0.439 & 82.24 \\
\hline 15 & 2 & 2 & 3 & 1 & 3 & 1 & 2 & 1 & 2 & 3 & 2 & 3 & 1 & 0.456 & 96.24 \\
\hline 16 & 2 & 3 & 1 & 2 & 1 & 2 & 3 & 3 & 1 & 2 & 2 & 3 & 1 & 0.299 & 71.07 \\
\hline 17 & 2 & 3 & 1 & 2 & 2 & 3 & 1 & 1 & 2 & 3 & 3 & 1 & 2 & 0.308 & 89.68 \\
\hline 18 & 2 & 3 & 1 & 2 & 3 & 1 & 2 & 2 & 3 & 1 & 1 & 2 & 3 & 0.336 & 106.2 \\
\hline 19 & 3 & 1 & 3 & 2 & 1 & 3 & 2 & 1 & 3 & 2 & 1 & 3 & 2 & 0.383 & 57.24 \\
\hline 20 & 3 & 1 & 3 & 2 & 2 & 1 & 3 & 2 & 1 & 3 & 2 & 1 & 3 & 0.409 & 67.93 \\
\hline 21 & 3 & 1 & 3 & 2 & 3 & 2 & 1 & 3 & 2 & 1 & 3 & 2 & 1 & 0.419 & 83.21 \\
\hline 22 & 3 & 2 & 1 & 3 & 1 & 3 & 2 & 2 & 1 & 3 & 3 & 2 & 1 & 0.387 & 59.24 \\
\hline 23 & 3 & 2 & 1 & 3 & 2 & 1 & 3 & 3 & 2 & 1 & 1 & 3 & 2 & 0.452 & 67.93 \\
\hline 24 & 3 & 2 & 1 & 3 & 3 & 2 & 1 & 1 & 3 & 2 & 2 & 1 & 3 & 0.409 & 83.21 \\
\hline 25 & 3 & 3 & 2 & 1 & 1 & 3 & 2 & 3 & 2 & 1 & 2 & 1 & 3 & 0.363 & 65.58 \\
\hline 26 & 3 & 3 & 2 & 1 & 2 & 1 & 3 & 1 & 3 & 2 & 3 & 2 & 1 & 0.395 & 89.09 \\
\hline 27 & 3 & 3 & 2 & 1 & 3 & 2 & 1 & 2 & 1 & 3 & 1 & 3 & 2 & 0.334 & 113.77 \\
\hline
\end{tabular}

near the normal load sensor and carries a counter weight at one end, while at the other end, a loading pan is suspended for placing the dead weights. The load is applied by placing dead weight in a loading pan which is connected by a lever. The experimental data is recorded by a computer attached with the apparatus. The wear is measured in terms of wear depth (microns) and friction in terms of coefficient of friction. It may be noted here that wear behaviour is normally expressed as wear volume or weight loss, while in the present experimental set up, wear is measured in terms of displacement. Thus, to access the accuracy of wear measurement, the displacement results for wear are compared with weight loss and it shows almost linear relationship for the range of test parameters considered in the present study. Moreover, since in the present study time is taken as a design parameter to study tribological performance, it is not possible to go for wear measurement through weight loss as that requires off-line measurement. Hence, wear has been measured in terms of wear depth in situ. The wear tests are carried out as per $\mathrm{L}_{27}$ orthogonal array in Table 3.

4.4. Microstructure Study. After wear tests, scanning electron microscopy (JEOL, JSM 6360) is done to evaluate the microstructure of the specimen. The SEM evaluation is performed at different magnifications ranging from 250 to 1000 at constant electron beam energy of $20 \mathrm{Kv}$. From the SEM images, it is determined that whether the wear tracks are adhesive or abrasive in nature.

\section{Result and Discussion}

The objective of the present study is to minimize friction and wear for $\mathrm{Al}-7.5 \% \mathrm{SiCp}$ metal matrix composite using the Taguchi method. The tribological testing is carried out using three control parameters, namely, applied load, sliding speed, and time. Coefficients of friction and wear depth are taken as system responses. The experimental results for friction and wear tests are shown in Table 3. Grey relational analysis is carried out following the steps mentioned earlier. Table 4 shows the calculated values for each steps of grey relational analysis.

5.1. Analysis of $S / N$ Ratio for Grey Relational Grade. The normal method of calculating the desirable factors levels is to look at simple averages of the results. But the variability of results within a trial condition cannot be judged by this method. Thus, signal-to-noise ratio analysis is done considering wear as the performance index. The analysis is carried 


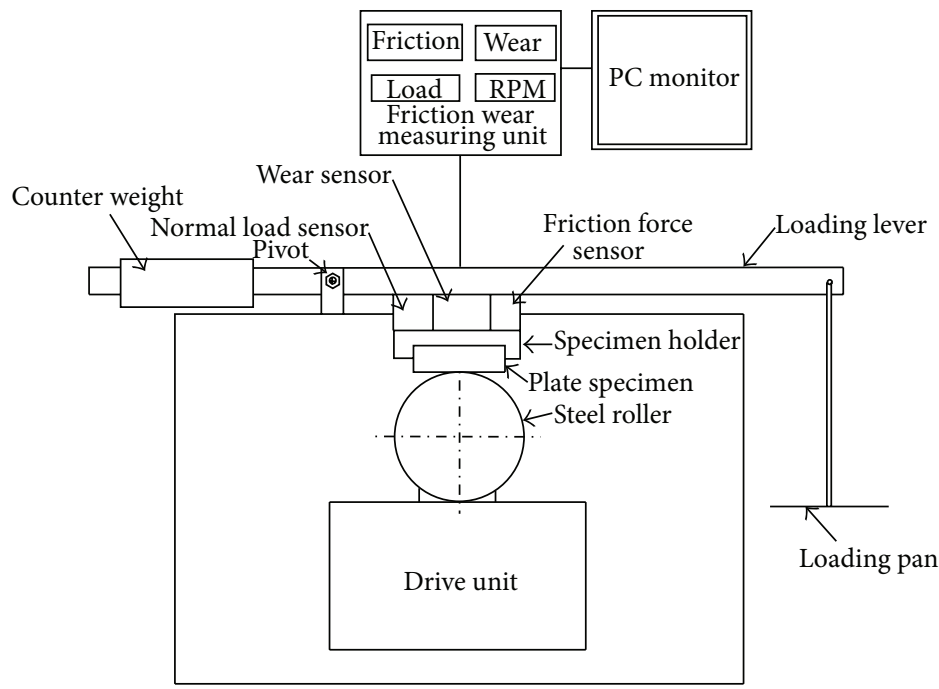

FIGURE 1: Layout of multitribotester.

TABLE 4: Computation of Grey Relational Grade.

\begin{tabular}{|c|c|c|c|c|c|c|c|c|c|}
\hline \multirow{2}{*}{$\begin{array}{l}\text { Exp. } \\
\text { no. }\end{array}$} & \multicolumn{2}{|c|}{ Experimental data } & \multicolumn{2}{|c|}{ Normalized data } & \multicolumn{2}{|c|}{ Value of $\Delta$} & \multicolumn{2}{|c|}{ Grey relational coefficient } & \multirow{2}{*}{$\begin{array}{l}\text { Grey relational } \\
\text { grade }\end{array}$} \\
\hline & $\mathrm{COF}$ & Wear $(\mu \mathrm{m})$ & $\begin{array}{l}\text { Normalized } \\
\text { COF }\end{array}$ & $\begin{array}{c}\text { Normalized } \\
\text { WEAR }\end{array}$ & $\Delta$ value $\mathrm{COF}$ & $\Delta$ value WEAR & $\xi$ value $\mathrm{COF}$ & $\xi$ value WEAR & \\
\hline 1 & 0.341 & 60.07 & 0.7529 & 0.8439 & 0.2471 & 0.1561 & 0.6693 & 0.7621 & 0.7157 \\
\hline 2 & 0.321 & 71.84 & 0.8706 & 0.6590 & 0.1294 & 0.3410 & 0.7944 & 0.5945 & 0.6944 \\
\hline 3 & 0.387 & 85.24 & 0.4824 & 0.4484 & 0.5176 & 0.5516 & 0.4913 & 0.4755 & 0.4834 \\
\hline 4 & 0.323 & 79.44 & 0.8588 & 0.5395 & 0.1412 & 0.4605 & 0.7798 & 0.5206 & 0.6502 \\
\hline 5 & 0.373 & 94.89 & 0.5647 & 0.2967 & 0.4353 & 0.7033 & 0.5346 & 0.4155 & 0.4751 \\
\hline 6 & 0.303 & 107.9 & 0.9765 & 0.0923 & 0.0235 & 0.9077 & 0.9551 & 0.3552 & 0.6551 \\
\hline 7 & 0.316 & 50.14 & 0.9000 & 1.0000 & 0.1000 & 0.0000 & 0.8333 & 1.0000 & 0.9167 \\
\hline 8 & 0.348 & 69.63 & 0.7118 & 0.6937 & 0.2882 & 0.3063 & 0.6343 & 0.6201 & 0.6272 \\
\hline 9 & 0.312 & 86.03 & 0.9235 & 0.4360 & 0.0765 & 0.5640 & 0.8673 & 0.4699 & 0.6686 \\
\hline 10 & 0.396 & 50.63 & 0.4294 & 0.9923 & 0.5706 & 0.0077 & 0.4670 & 0.9848 & 0.7259 \\
\hline 11 & 0.469 & 61.39 & 0.0000 & 0.8232 & 1.0000 & 0.1768 & 0.3333 & 0.7388 & 0.5361 \\
\hline 12 & 0.462 & 77.16 & 0.0412 & 0.5754 & 0.9588 & 0.4246 & 0.3427 & 0.5407 & 0.4417 \\
\hline 13 & 0.397 & 64.45 & 0.4235 & 0.7751 & 0.5765 & 0.2249 & 0.4645 & 0.6898 & 0.5771 \\
\hline 14 & 0.439 & 82.24 & 0.1765 & 0.4955 & 0.8235 & 0.5045 & 0.3778 & 0.4978 & 0.4378 \\
\hline 15 & 0.456 & 96.24 & 0.0765 & 0.2755 & 0.9235 & 0.7245 & 0.3512 & 0.4083 & 0.3798 \\
\hline 16 & 0.299 & 71.07 & 1.0000 & 0.6711 & 0.0000 & 0.3289 & 1.0000 & 0.6032 & 0.8016 \\
\hline 17 & 0.308 & 89.68 & 0.9471 & 0.3786 & 0.0529 & 0.6214 & 0.9043 & 0.4459 & 0.6751 \\
\hline 18 & 0.336 & 106.2 & 0.7824 & 0.1190 & 0.2176 & 0.8810 & 0.6967 & 0.3620 & 0.5294 \\
\hline 19 & 0.383 & 57.24 & 0.5059 & 0.8884 & 0.4941 & 0.1116 & 0.5030 & 0.8176 & 0.6603 \\
\hline 20 & 0.409 & 67.93 & 0.3529 & 0.7204 & 0.6471 & 0.2796 & 0.4359 & 0.6414 & 0.5386 \\
\hline 21 & 0.419 & 83.21 & 0.2941 & 0.4803 & 0.7059 & 0.5197 & 0.4146 & 0.4903 & 0.4525 \\
\hline 22 & 0.387 & 59.24 & 0.4824 & 0.8570 & 0.5176 & 0.1430 & 0.4913 & 0.7776 & 0.6345 \\
\hline 23 & 0.452 & 67.93 & 0.1000 & 0.7204 & 0.9000 & 0.2796 & 0.3571 & 0.6414 & 0.4993 \\
\hline 24 & 0.409 & 83.21 & 0.3529 & 0.4803 & 0.6471 & 0.5197 & 0.4359 & 0.4903 & 0.4631 \\
\hline 25 & 0.363 & 65.58 & 0.6235 & 0.7573 & 0.3765 & 0.2427 & 0.5705 & 0.6733 & 0.6219 \\
\hline 26 & 0.395 & 89.09 & 0.4353 & 0.3879 & 0.5647 & 0.6121 & 0.4696 & 0.4496 & 0.4596 \\
\hline 27 & 0.334 & 113.77 & 0.7941 & 0.0000 & 0.2059 & 1.0000 & 0.7083 & 0.3333 & 0.5208 \\
\hline
\end{tabular}




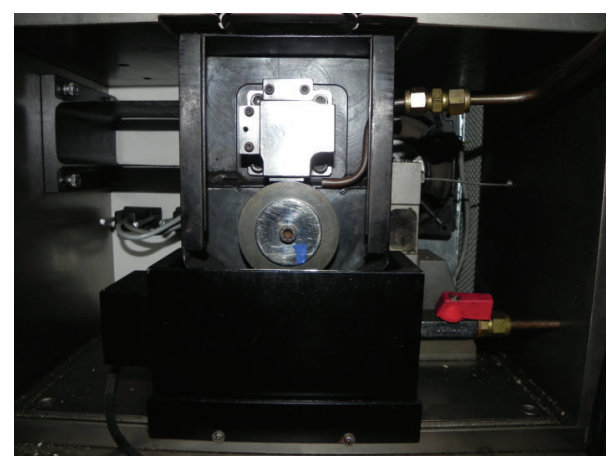

FIGURE 2: Close-up view of specimen loading in multitribotester.

TABLE 5: Response table for grey relational grade.

\begin{tabular}{lccc}
\hline Level & Load & Speed & Time \\
\hline 1 & 0.654 & 0.583 & 0.7004 \\
2 & 0.5672 & 0.530 & 0.5492 \\
3 & 0.5389 & 0.647 & 0.5105 \\
Rank & 3 & 2 & 1 \\
Delta & 0.1151 & 0.117 & 0.1899 \\
\hline
\end{tabular}

Total mean grey relational grade $=0.5867$.

out using lower-the-better criterion and the same is expressed as

$$
\frac{S}{N}=-10 \log \left(\sum \frac{y^{2}}{n}\right) .
$$

Here, $y$ is the experimental data and $n$ is the number of experiments. Table 3 shows the experimental results for tribological tests. The experimental design being orthogonal, it is possible to separate out the effect of each control factor at different levels. As an example, the mean $S / N$ ratio for factor $L$ (load) at levels 1,2 , and 3 can be calculated by averaging the $S / N$ ratios for the experiments $1-9,10-18$, and 19-27, respectively. The mean $S / N$ ratio for the other factors at different levels can be calculated in a similar manner. In the response table (Table 5), the mean $S / N$ ratio for each level of the controlling factors is shown. In addition, the total mean $S / N$ ratio for the 27 experiments is also calculated and listed in the same table. All the calculations are performed using Minitab software [23]. The response table includes ranks based on delta value (the highest average of each factor minus the lowest average of the same); rank 1 is assigned to the parameter with highest delta value, rank 2 to second highest delta value and so on. In this case, time has the highest delta value thus rank 1 is assigned to time $(T)$. The corresponding main effects plot for mean is shown in Figure 3. The interaction plots for parameters applied load, sliding speed, and time are given in Figures 4, 5, and 6. In main effects plot, the significance of each parameter can be judged by the inclination of plot. The parameter with highest inclination line has greater significance than the rest on the tribological behaviour of the material. From the main effects plot, it is seen that the parameter time $T$ is the most significant parameter, while other parameters $L$ (load) and $S$ (speed) are also significant

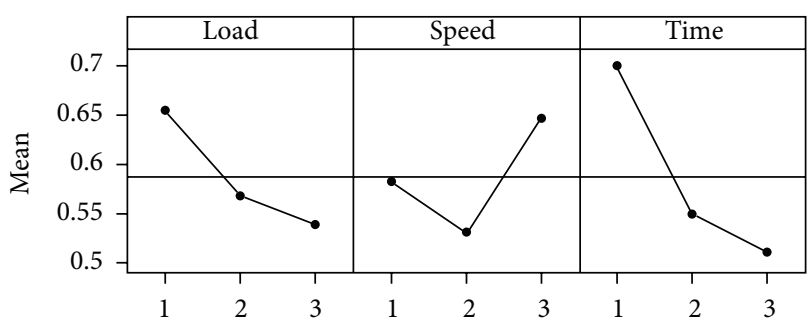

Figure 3: Main effects plot for grey relational grade.

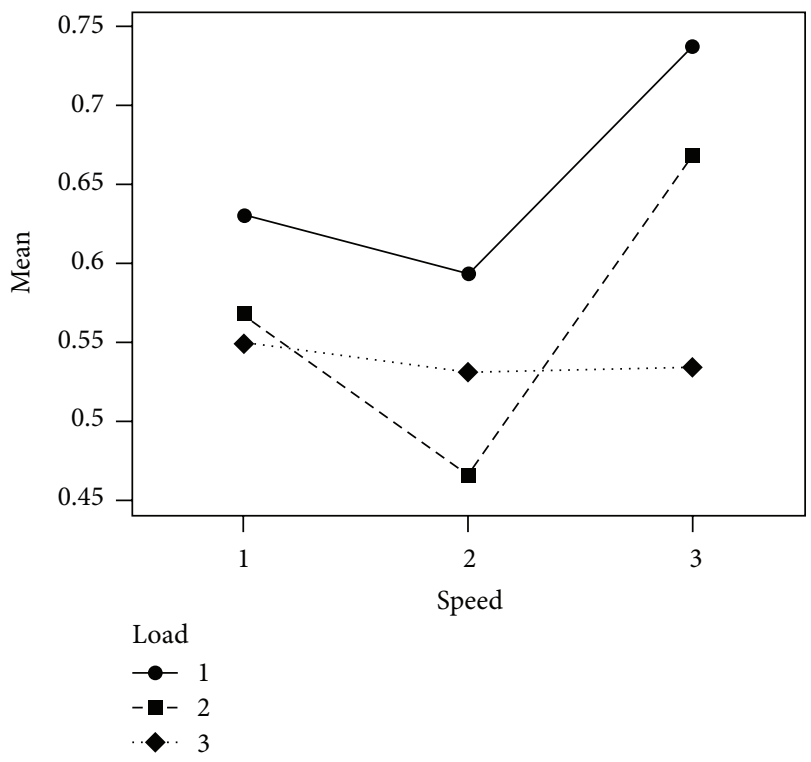

FIGURE 4: Interaction plot between load and speed.

parameters in controlling the tribological behaviour of the MMC. The interaction plots are studied on the basis of nonparallelism of the parameter effects. If the lines of an interaction plots are not parallel or intersecting, then there is strong interactions between the parameters. And if the lines are parallel to each other, then there is nominal or no interaction between them. From the interaction plots in Figures 4, 5, and 6 , it can be seen that the lines are intersecting each other. Thus, there is good interaction between the parameters. From the present analysis, it is observed that time $(T)$ is the most influencing parameter for tribological characteristics of $\mathrm{Al}$ SiCp composites followed by sliding speed and applied load, respectively. The optimal process parameter combination is the one that yields maximum mean value, and thus, it is found to be L1S3T1, that is, the lowest level of applied load along with the highest level of sliding speed and lowest level of sliding time within the experimental domain considered in the present study.

5.2. Analysis of Variance for Grey Relational Grade. ANOVA is a statistical technique which can infer some important conclusions based on analysis of the experimental data. This method is rather useful for revealing the level of significance of the influence of factor(s) or their interaction on a particular 
TABLE 6: Results of ANOVA for grey relational grade.

\begin{tabular}{lccccc}
\hline Source & DF & SS & MS & $F$ & Contribution $\%$ \\
\hline$L$ & 2 & 0.064785 & 0.032392 & $7.08^{\#}$ & 15.6 \\
$S$ & 2 & 0.061299 & 0.03065 & $6.7^{\#}$ & 14.76 \\
$T$ & 2 & 0.181288 & 0.090644 & $19.8^{*}$ & 43.65 \\
$L * S$ & 4 & 0.035076 & 0.008769 & 0.64 & 8.45 \\
$L * T$ & 4 & 0.01168 & 0.00292 & 1.34 & 2.81 \\
$S * T$ & 4 & 0.024569 & 0.006142 & & 8.91 \\
Error & 8 & 0.036623 & 0.004578 & & 8.82 \\
\hline Total & 26 & 0.415319 & & &
\end{tabular}

Significant parameters and interactions $-\left({ }^{*} F_{0.01,2,8}=8.65,{ }^{\#} F_{0.05,2,8}=4.46\right)$.

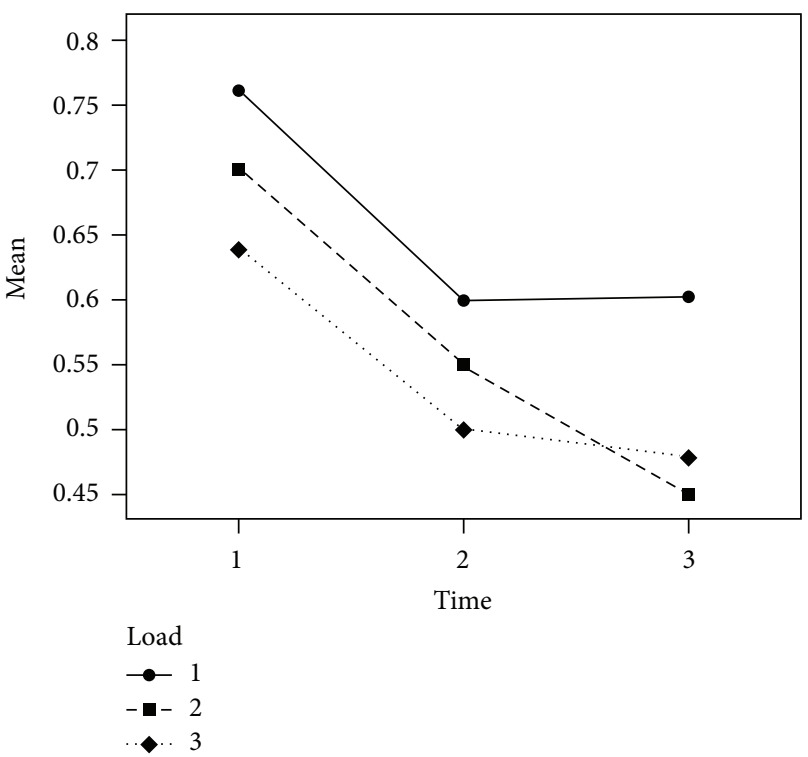

FIgURE 5: Interaction plot between load and time.

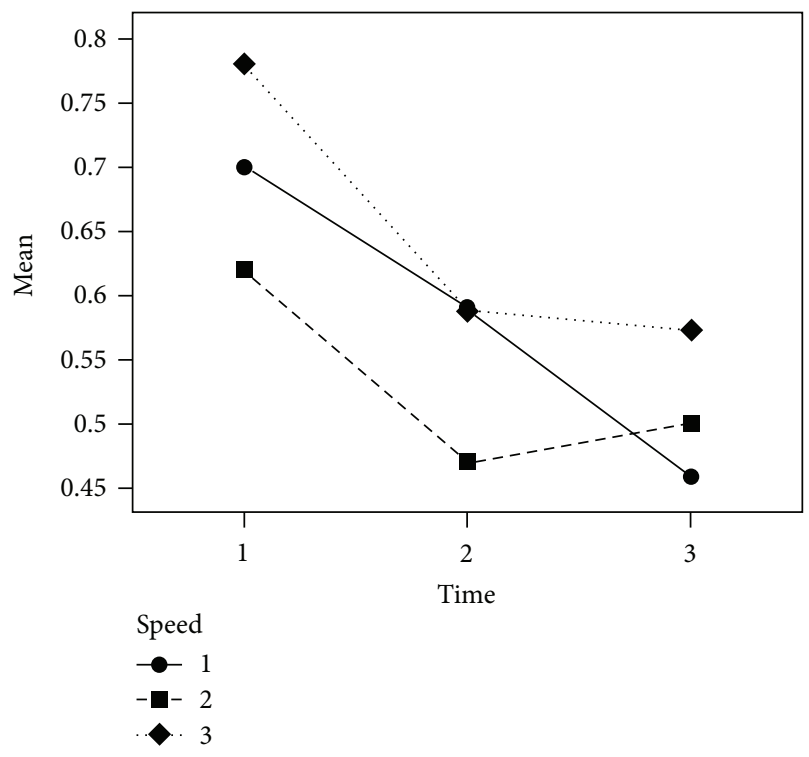

FIGURE 6: Interaction plot between speed and time. response. It separates the total variability of the response into contributions of each of the factors and the error. Using Minitab [23], ANOVA is performed to determine which parameter and interaction significantly affect the performance characteristics. Table 6 shows the ANOVA result for tribological behaviour of Al-SiCp metal matrix composites. ANOVA calculates the $F$-ratio, which is the ratio between the regression mean square and the mean square error. The $F$-ratio, also called the variance ratio, is the ratio of variance due to the effect of a factor and variance due to the error term. This ratio is used to measure the significance of the parameters under investigation with respect to the variance of all the terms included in the error term at the desired significance level, $\alpha$. If the calculated value of the $F$-ratio is higher than the tabulated value of the $F$-ratio, then the factor is significant at a desired $\alpha$ level. In general, when the $F$ value increases the significance of the parameter also increases. The ANOVA table shows the percentage contribution of each parameter. From the ANOVA table, it is seen that parameter $T$, that is, time, is the most significant parameter influencing the tribological behaviour at the confidence level of $99 \%$, while parameters $L$ (applied load) and $S$ (sliding speed) are significant at the confidence level of $95 \%$. The interactions of parameters have almost no influence on friction and wear property of the composite. The literature review shows that the load was more effective than others. However, to the best of the authors' knowledge, no study is available where time has been considered as a parameter. Typically, researchers so far have considered load (contact pressure) and speed (sliding velocity) as the parameters since wear characteristics mainly depend on so-called "PV (pressure-velocity)" factor. In the present study, tribological performance of the composite has been evaluated considering both friction and wear as response variables in a flat-on-roller configuration. The flat specimen is held against rotating roller counterface. Thus, to consider the effect of sliding distance, both speed of the roller and time of contact have been included as design factors along with load. For the combined response of friction and wear, finally, time appears as the most dominant factor controlling the tribological behavior. 
TABLE 7: Results of confirmation test of multiple performance.

\begin{tabular}{lccc}
\hline & Initial parameter & Optimal parameter & Exp. \\
\hline Level & L2S2T2 & L1S3T1 & L1S3T1 \\
Wear $(\mu \mathrm{m})$ & 82.24 & & 50.14 \\
COF & 0.439 & & 0.316 \\
Grade & 0.4378 & 0.3456 & 0.9167 \\
\hline
\end{tabular}

Improvement of grey relational grade $=0.0922$.

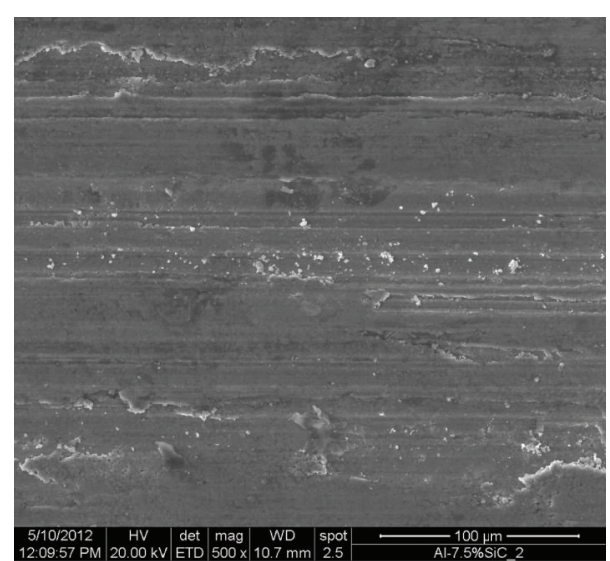

Figure 7: SEM of Al-7.5\% SiCp worn surface at 500x magnification.

5.3. Confirmation Tests. After the optimal level of testing parameters has been found, it is necessary that verification tests are carried out in order to evaluate the accuracy of the analysis and to validate the experimental results. The estimated $S / N$ ratio $\hat{\eta}$, using the optimal level of the testing parameters, can be calculated as

$$
\widehat{\eta}=\eta_{m}+\sum_{i=1}^{o}\left(\bar{\eta}_{i}-\eta_{m}\right)
$$

where $\eta_{m}$ is the total mean $S / N$ ratio, $\bar{\eta}_{i}$ is the mean $S / N$ ratio at the optimal testing parameter level, and $o$ is the number of main design process parameters that significantly affect the friction and wear performance of Al-7.5\% SiCp MMC. The confirmation tests for all the experiments are presented in the following section.

Table 7 shows the comparison of the estimated grey relational grade with the actual grey relational grade using the optimal parameters. The improvement of grey relational grade from initial to optimal condition is 0.0922 . Thus, there is an improvement of $21 \%$ in grey relational grade.

5.4. Microstructure Analysis. Microstructure study of the wear tracks is carried out to analyze the wear mechanism that the composites undergo during tribological testing. Figures 7 and 8 show wear tracks of $\mathrm{Al}-7.5 \%$ SiCp samples having undergone tribological testing. From the SEM micrographs, it can be observed that the worn surface mainly consists of longitudinal grooves and partially irregular pits. The presence of grooves indicates microcutting and microploughing effect. Thus, wear mechanism is found to be dominated by abrasive

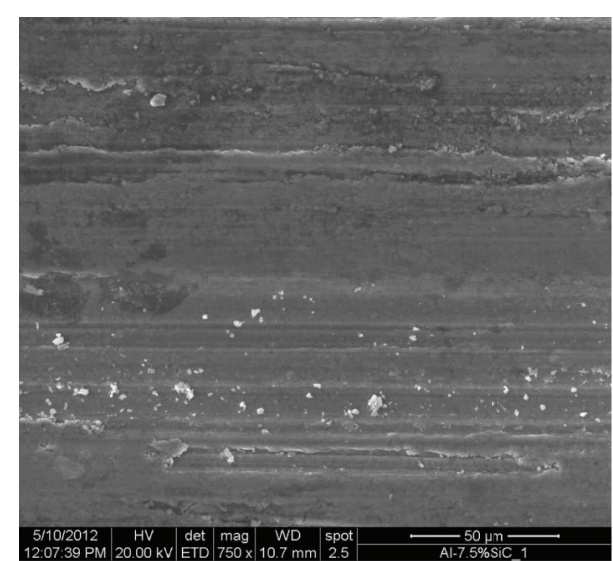

FIGURE 8: SEM of Al-7.5\% SiCp worn surface at 750x magnification.

wear. Also, presence of pits and prows can be observed in the micrographs; thus, occurrence of adhesive wear is also visible. So, from overall microstructure study, it can be concluded that mostly abrasive wear has taken place with some traces of adhesive wear. Typical wear surface of such materials under mild wear conditions [1] consists of three different layers: plastic deformation layer characterized by deformed or inclined grains, oxide layer composed of iron oxide, aluminium matrix and small fractured $\mathrm{SiC}$ particles, and the transfer layer containing numerous microcracks as a result of microcutting by fractured $\mathrm{SiC}$ particles. The present observations on wear mechanism match well with other studies. However, there is ample scope for future study to consider the wear mechanism under different test conditions.

In the present investigation, the effect of process parameters applied load, sliding speed, and time on the tribological behaviour of Al-SiCp composite is studied. Apart from these, other factors like volume fraction of reinforcement, heat treatment, temperature variation, and particle size of reinforcement are assumed constant during this experimental study. In the future, studies related to effects of these other factors on the tribological behaviour of Al-SiCp can be carried out.

\section{Conclusion}

The tribological behaviour of $\mathrm{Al}-7.5 \% \mathrm{SiCp}$ metal matrix composite is studied for varying applied load, sliding speed, and time using the Taguchi orthogonal array design and grey relational grade. The multiple responses friction and wear are simplified to grey relational grade for the analysis process. 
It is observed that parameter $T$, that is, time, is the most significant parameter influencing the tribological behaviour at the confidence level of $99 \%$, while parameters $L$ (applied load) and $S$ (sliding speed) are also significant at $95 \%$ confidence level. The interactions between the parameters have almost no influence on friction and wear property of the composite. From the Taguchi analysis, the optimal combination of process parameter for minimum friction and wear is found to be L1S3T1, that is, the highest level of sliding speed along with the lowest levels of applied load and time. Wear depth is reduced by nearly $39 \%$ from initial to optimal process parameter condition, and friction is reduced by $28 \%$. From the present study, it is revealed that a proper control of process parameters can result in improved design of the Al-SiCp composite for tribological applications. From the microstructure study of worn surfaces, it is observed that mostly abrasive wear mechanism has occurred on the wear tracks with some traces of adhesive wear mechanism.

\section{Conflict of Interests}

The authors of the paper do not have a direct financial relation with the commercial identity mentioned in their paper that might lead to a conflict of interests for any of the authors.

\section{References}

[1] T. Ma, H. Yamaura, D. A. Koss, and R. C. Voigt, "Dry sliding wear behavior of cast SiC-reinforced Al MMCs," Materials Science and Engineering A, vol. 360, no. 1-2, pp. 116-125, 2003.

[2] Y. Yalcin and H. Akbulut, "Dry wear properties of A356-SiC particle reinforced MMCs produced by two melting routes," Materials and Design, vol. 27, no. 10, pp. 872-881, 2006.

[3] S. C. Sharma, B. M. Girish, R. Kamath, and B. M. Satish, "Effect of $\mathrm{SiC}$ particle reinforcement on the unlubricated sliding wear behaviour of ZA-27 alloy composites," Wear, vol. 213, no. 1-2, pp. 33-40, 1997.

[4] S. Ghosh, R. Behera, G. Sutradhar, and P. Sahoo, "Optimization of friction performance of $\mathrm{Al}-5 \% \mathrm{SiC}$ metal matrix composite using Taguchi method," Journal of Tribology Research, vol. 1, no. 2, pp. 83-89, 2010.

[5] S. Ghosh, P. Sahoo, and G. Sutradhar, "Friction performance of Al-10\% SiCp reinforced metal matrix composite using Taguchi Method," ISRN Tribology, vol. 2013, Article ID 386861, 9 pages, 2013.

[6] A. Onat, "Mechanical and dry sliding wear properties of silicon carbide particulate reinforced aluminium-copper alloy matrix composites produced by direct squeeze casting method," Journal of Alloys and Compounds, vol. 489, no. 1, pp. 119-124, 2010.

[7] H. Ahlatci, E. Candan, and H. Cimenoglu, "Abrasive wear behavior and mechanical properties of Al-Si/SiC composites," Wear, vol. 257, no. 5-6, pp. 625-632, 2004.

[8] Y. Sahin, "Optimization of testing parameters on the wear behaviour of metal matrix composites based on the Taguchi method," Materials Science and Engineering A, vol. 408, no. 12, pp. 1-8, 2005.

[9] Y. Şahin, "Abrasive wear behaviour of SiC/2014 aluminium composite," Tribology International, vol. 43, no. 5-6, pp. 939943,2010 .
[10] K. S. Al-Rubaie, H. N. Yoshimura, and J. D. Biasoli De Mello, "Two-body abrasive wear of Al-SiC composites," Wear, vol. 233235, pp. 444-454, 1999.

[11] K. S. Al-Rubaie, H. Goldenstein, and J. D. Biasoli De Mello, "Three-body abrasion of Al-SiC composites," Wear, vol. 225229, pp. 163-173, 1999.

[12] G. J. Howell and A. Ball, "Dry sliding wear of particulatereinforced aluminium alloys against automobile friction materials," Wear, vol. 181-183, no. 1, pp. 379-390, 1995.

[13] R. N. Rao and S. Das, "Effect of matrix alloy and influence of SiC particle on the sliding wear characteristics of aluminium alloy composites," Materials and Design, vol. 31, no. 3, pp. 1200-1207, 2010.

[14] R. N. Rao and S. Das, "Effect of sliding distance on the wear and friction behavior of as cast and heat-treated Al-SiCp composites," Materials and Design, vol. 32, no. 5, pp. 3051-3058, 2011.

[15] A. Martín, M. A. Martínez, and J. Llorca, "Wear of SiC-reinforced Al-matrix composites in the temperature range 20-200," Wear, vol. 193, no. 2, pp. 169-179, 1996.

[16] G. Straffelini, M. Pellizzari, and A. Molinari, "Influence of load and temperature on the dry sliding behaviour of Al-based metal-matrix-composites against friction material," Wear, vol. 256, no. 7-8, pp. 754-763, 2004.

[17] G. Taguchi, Introduction to Quality Engineering, Asian Productivity Organization, Tokyo, Japan, 1990.

[18] R. K. Roy, A Primer on Taguchi Method, Van Nostraid Reinhold, New York, NY, USA, 1990.

[19] P. J. Ross, Taguchi Techniques for Quality Engineering, McGrawHill, New York, NY, USA, 2nd edition, 1996.

[20] D. C. Montgomery, Design and Analysis of Experiments, John Wiley \& Sons, New York, NY, USA, 2001.

[21] R. A. Fisher, Design of Experiments, Oliver \& Boyd, Edinburgh, UK, 1951.

[22] J. Deng, "Introduction to grey system," Journal of Grey System, vol. 1, no. 1, pp. 1-24, 1989.

[23] Minitab User Manual (Release 13.2), Making Data Analysis Easier, MINITAB Inc, State College, Pa, USA, 2001. 

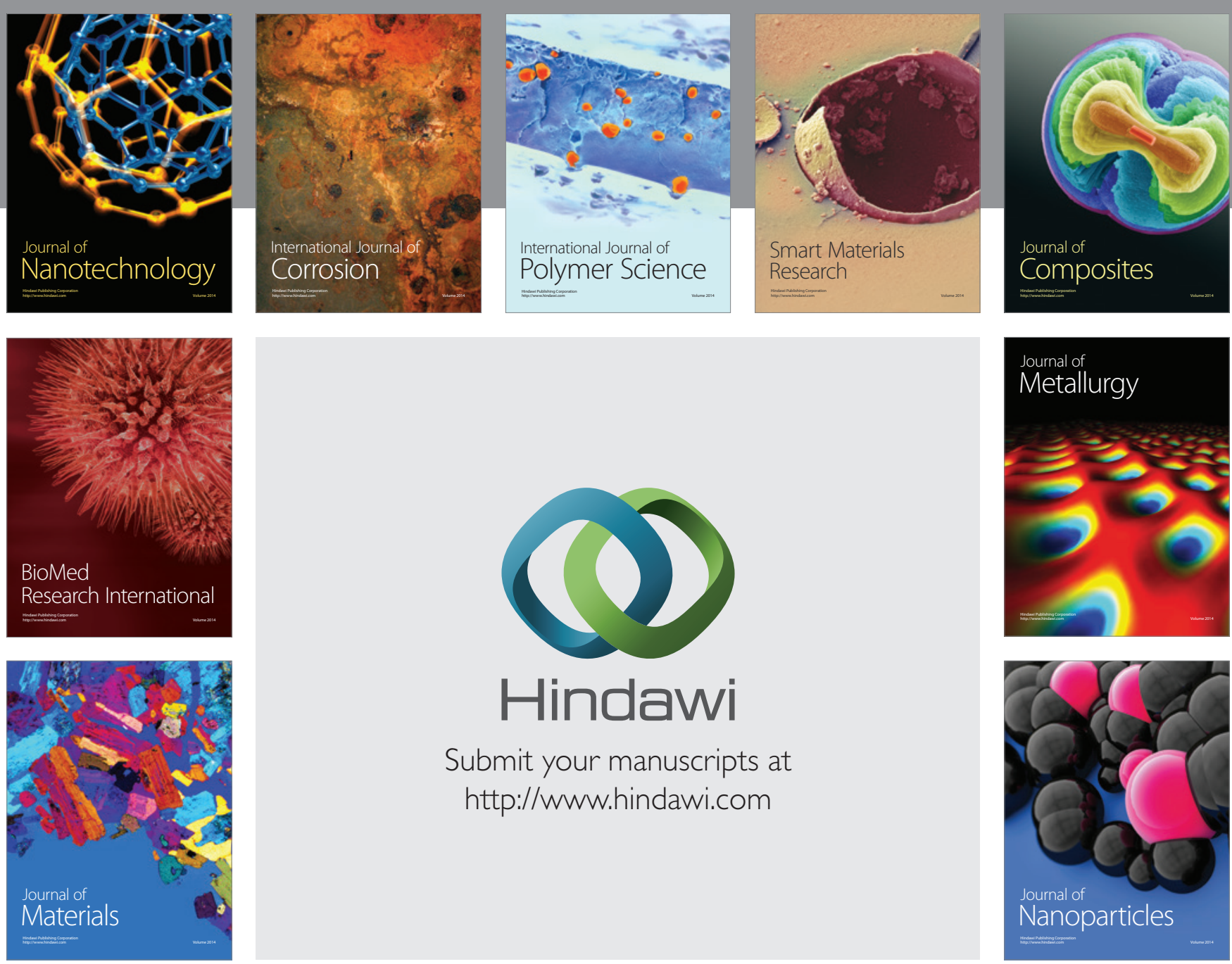

Submit your manuscripts at http://www.hindawi.com
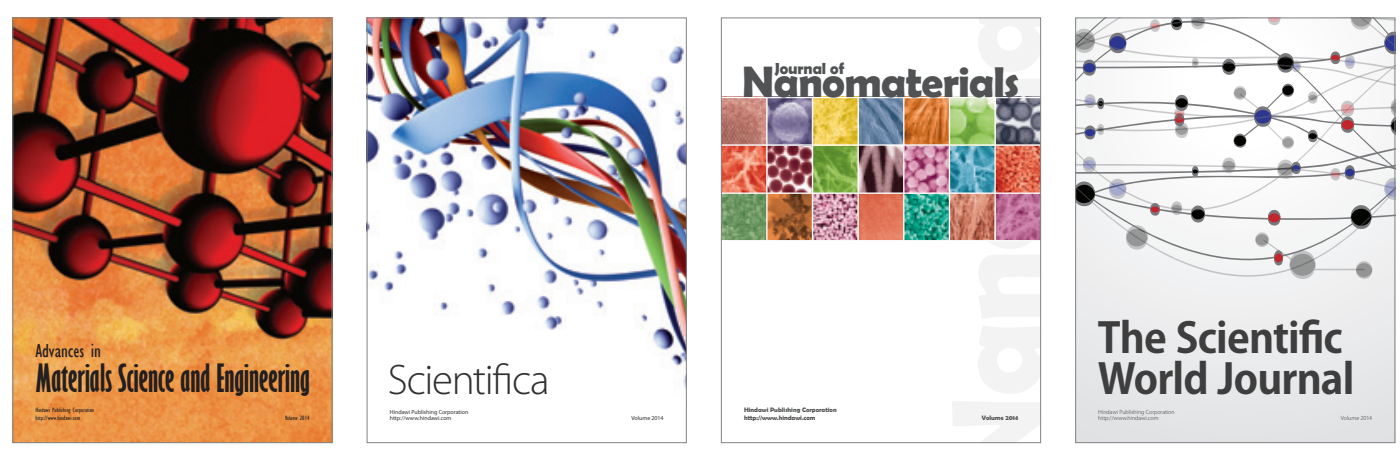

\section{The Scientific World Journal}
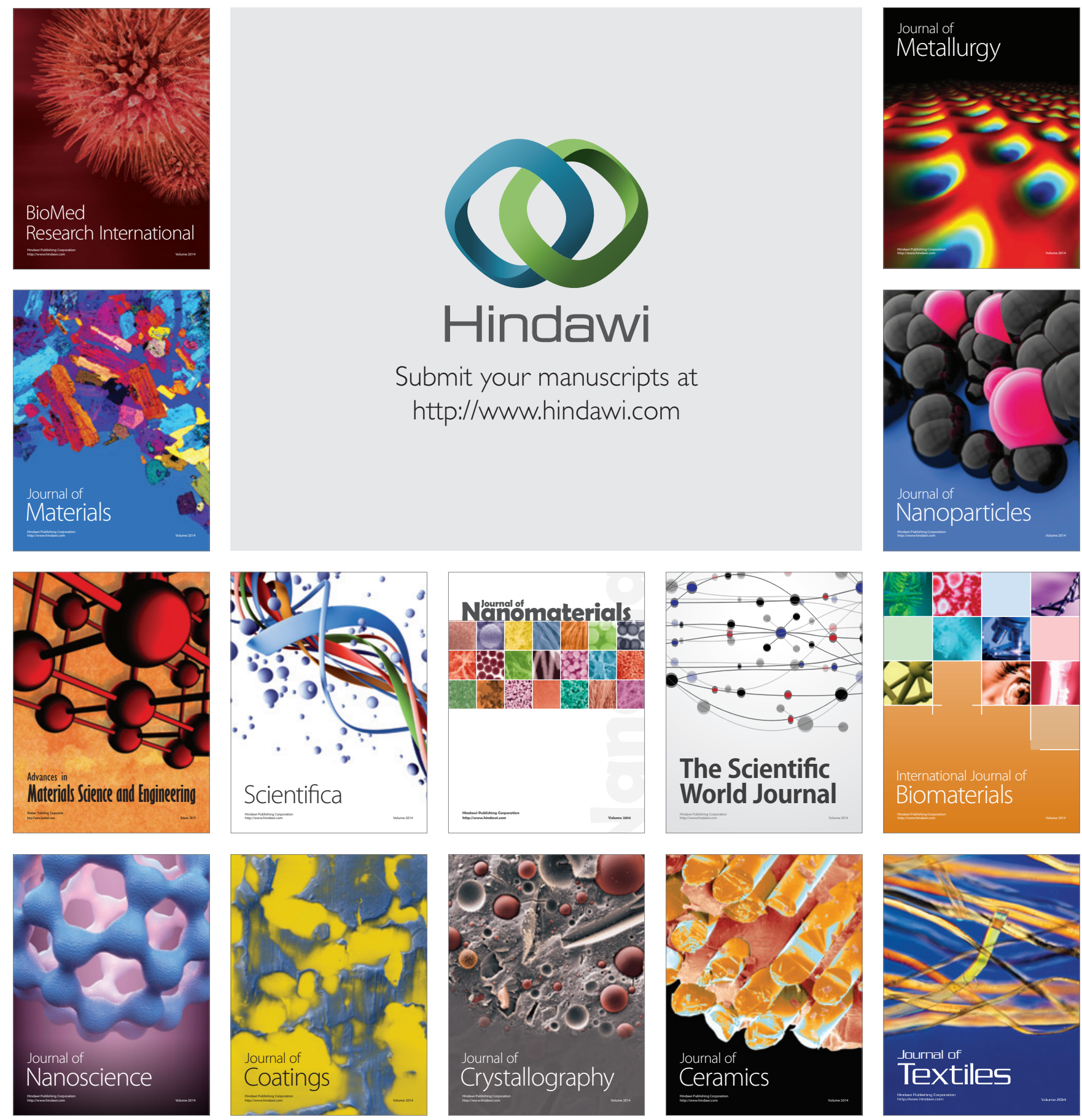